\title{
Warehouse Management Models Using Artificial Intelligence Technology with Application at Receiving Stage - A Review
}

\author{
Judy X Yang, Lily D Li, and Mohammad G. Rasul
}

\begin{abstract}
This paper reviewed recent literature on inventory management technologies and Artificial Intelligence (AI) applications. The classical Artificial Neural Network (ANN) models and computer vision technology applications for object classification were reviewed in particularly. The challenges of AI technologies in industrial warehouse management, particularly the ANN for solving object classification and counting are discussed. Some researchers reported the use of face recognition, moving vehicle classification and counting, which are easy to recognise objects on the floor or the ground. Other researchers explored the object counting technologies which are used to identify the visible objects on the ground or in images. Although several studies focused on industrial component identification and counting problems, a study on the warehouse receiving stage remains a blank canvas. This paper reviews and analyses current industrial warehouse management developments around AI applications in this field, which may provide a reference for future researchers and end-users for the best modelling approach to this specific problem at the warehouse receiving stage.
\end{abstract}

Index Terms-Warehouse management, classification, counting, convolutional neuron net.

\section{INTRODUCTION}

In production and operations management, both SAP and J.D. Edward (JDE) enterprise management systems are prevalent in the industrial fields [1], [2]. These are convenient tools to provide inventory monitoring, production planning and order management, which have brought benefits to the industry. However, in warehouse management, these enterprise systems require raw material data to be controlled manually [3]-[5]. Human error cannot be avoided during this operation, which is the primary reason for errors in data management [4], [6]-[8].

Human behaviour causing wrong information to be recorded at the receiving stage has been perplexing enterprise management over the last decades [9].

The data accuracy in the warehouse system module is the foundation of the production plan and supply chain management. However, human behaviour usually causes data error in actual operation. Both academics and enterprise management have addressed this problem. Most of the research in this field has been striving to explore a new

Manuscript received November 4, 2019; revised July 19, 2020.

Judy X Yang, Lily D Li, and Mohammad G. Rasul are with the School of Engineering and Technology, CQUniversity, Rockhampton, QLD 4702, Australia (e-mail: j.yang@cqu.edu.au, 1.li@cqu.edu.au, m.rasul@cqu.edu.au) solution or technology to minimise or eliminate the problem caused by human error [9]. A large number of ANN models have been developed over the past decade. Supply chain management has been gradually adopting AI in sales data analysis, and customer demands analysis and warehouse production order distribution [10]-[13]. Some models have been developed to classify and identify the stock level [14]-[17]. However, the challenging problem prevalent in this domain is counting objects based on their classification. Very few studies have examined object counting in the warehouse management field.

A series of recent studies have indicated that warehouse management plays a vital role in industrial productivity and better customer service [14], [18], [19]. The correct warehouse information can make production smoother and ensures that shipping of commercial goods to the customer occurs on schedule [20]-[22]. However, in practical operations, erroneous data information can often cause a massive loss to the company. Therefore, in the past decade, researchers and management teams from industry fields have been seeking solutions to ensure the maintenance of correct data in warehouse management systems. There is a large body of literature related to supply chain management [3], [11], [23]-[27]. As a critical and fundamental part of the supply chain, warehouse management has always been an essential study area for researchers [6], [7], [21], [28]-[31].

However, one primary function of warehouse management, components receiving [21], still needs human involvement to control it, i.e., checking purchase orders and counting parts, and then inputting the data into the enterprise system. These receiving data is the fundamental base for all supply chain management and industry operations. Some researchers have been exploring how to build an AI model to solve inventory management problems [15], [16], [25], [31], [32]. Human error often causes a considerable loss at the warehouse receiving stage. This area is still a gap for researchers.

This paper examines several kinds of AI applications in warehouse management. It aims to provide researchers with indications of which are the better selections from the options available as set out in the following sections and create a suitable model from three sections.

Section II covers modern approaches for warehouse management and the currently available methods based on AI technologies. Section III reviews the classical Artificial Neural Network (ANN) models and their architectures for object classification and counting. Section IV presents the computer vision technology used for object tracking and identification. Section V describes results and challenges in 
the field, and Section VI concludes the paper with an overview of some crucial points.

\section{WAREHOUSE MANAGEMENT AND AI MODEL APPLICATIONS}

A literature search has been conducted based on primary keywords with subject areas of "inventory management", "artificial intelligence", "identification" and "counting" which assure coverage of an overall picture of artificial intelligence applications in the topic of warehouse management. This subsection mainly focuses on warehouse management and artificial intelligence application status in this domain

\section{A. Approaches for Classical Warehouse Management}

Over the past two decades, researchers focused on improving inventory management theory and tried to combine new technology with warehouse management systems [1], [20], [21], [33]-[37]. Barcode technology was widely used in inventory management to control stock levels. Some researchers pointed out solutions to integrate warehouse management systems with automated identification technology [32], [38]. Table I identifies typical literature published on warehouse management, which indicated that warehouse management led to a higher level of management. One warehouse expert outlines the world-class warehousing and material handling management system that provides a set of complete theories and practical operations for industries and businesses [14].

\section{B. AI Applications in Warehouse Management}

In the last decade, AI has been playing a part role in the supply chain management field. However, the research fields have been focusing on customer demands prediction, order fulfilment and components pick-up at various defined locations in the warehouse [15], [20], [21], [25], [26]. More recently, AI applications in supply chain management have seen tremendous improvements since 2010 [20], [21], [38]. Table II presents new technologies and AI model applications in warehouse management.

TABLE I: CLASSICAL WAREHOUSE MANAGEMENT APPROACHES

\begin{tabular}{|c|c|c|c|}
\hline Year/Title & Author(s) & Key Points & Application Model in Warehouse \\
\hline $\begin{array}{l}\text { 2001/Barcode technology for } \\
\text { inventory and marketing } \\
\text { management systems: A } \\
\text { model for its development and } \\
\text { implementation [19] }\end{array}$ & $\begin{array}{l}\text { Manthou and } \\
\text { Vlachopoulou }\end{array}$ & $\begin{array}{l}\text { This paper introduced a 2D barcode system, } \\
\text { with a case study applied in the business of a } \\
\text { drugstore supermarket chain. }\end{array}$ & $\begin{array}{l}\text { A barcode system is an appropriate solution for } \\
\text { businesses such as supermarkets and others requiring } \\
\text { in-process lot tracking. However, it is not suitable for } \\
\text { warehouse management because of labelling cost and } \\
\text { is time-consuming in the industrial field. }\end{array}$ \\
\hline $\begin{array}{l}\text { 2002/World-class } \\
\text { warehousing and material } \\
\text { handling [33] }\end{array}$ & Frazelle & $\begin{array}{l}\text { This book covers daily activities management } \\
\text { from warehouse parts receival to shipping. }\end{array}$ & $\begin{array}{l}\text { This book focuses on the principals of warehouse } \\
\text { management systems, and the data collection is under } \\
\text { human control using computer systems. }\end{array}$ \\
\hline $\begin{array}{l}\text { 2013/Organizing warehouse } \\
\text { management [4] }\end{array}$ & $\begin{array}{l}\text { Faber, N; de } \\
\text { Koster, } \\
\text { M.B.M; } \\
\text { Smidts, A }\end{array}$ & $\begin{array}{l}\text { This paper has investigated how } 215 \\
\text { warehouse management, understood as an } \\
\text { element of planning and control decisions and } \\
\text { all the procedures. These processes are found } \\
\text { to be organized and driven by task complexity } \\
\text { (TC) and market dynamics (MD). }\end{array}$ & $\begin{array}{l}\text { The paper covers current classical warehouse } \\
\text { management methods and provided a design } \\
\text { methodology approach. a multi-variable conceptual } \\
\text { model is developed based on the literature and tested } \\
\text { among } 215 \text { warehouses using a survey. }\end{array}$ \\
\hline
\end{tabular}

TABLE II: SELECTED AI APPLICATIONS In WAREHOUSE MANAGEMENT ARTICLES PUBLISHED IN 2010-2019

\begin{tabular}{|c|c|c|c|}
\hline Year/Title & Author(s) & Key Points & Application Model in Warehouse \\
\hline $\begin{array}{l}\text { 2011/Research and } \\
\text { Implementation on Web Services } \\
\text { Integration of Automatic } \\
\text { Identification System [42] }\end{array}$ & Yuan & $\begin{array}{l}\text { This paper outlined complete steps on } \\
\text { how to build an entire Automatic } \\
\text { Identification system to perform } \\
\text { material handling. }\end{array}$ & $\begin{array}{l}\text { The paper applied an Automatic Identification } \\
\text { system to perform material handling in the } \\
\text { warehouse based on product orders. }\end{array}$ \\
\hline $\begin{array}{l}\text { 2015/Genetic Scheduling and } \\
\text { Reinforcement Learning in } \\
\text { Multi-robot Systems for Intelligent } \\
\text { Warehouse [20] }\end{array}$ & $\begin{array}{l}\text { Dou, Chen, } \\
\text { and Yang }\end{array}$ & $\begin{array}{l}\text { The researchers provided a new hybrid } \\
\text { solution to improve the efficiency of } \\
\text { intelligent warehouses with multi-robot } \\
\text { systems; scheduling is combined with } \\
\text { reinforcement learning (RL). }\end{array}$ & $\begin{array}{l}\text { This paper mainly focuses on warehouse scheduling } \\
\text { and transition. The receiving operation was not } \\
\text { mentioned. }\end{array}$ \\
\hline $\begin{array}{l}\text { 2015/Generalized higher-level } \\
\text { automated innovation with } \\
\text { application to inventory } \\
\text { management [10] }\end{array}$ & $\begin{array}{l}\text { Bandaru, } \\
\text { Sunith; Aslam, } \\
\text { Tehseen; Ng, } \\
\text { Amos; Deb, } \\
\text { Kalyanmoy }\end{array}$ & $\begin{array}{l}\text { This paper generalizes the proposed } \\
\text { framework using genetic programming } \\
\text { in the context of higher-level innovation } \\
\text { through optimization. }\end{array}$ & $\begin{array}{l}\text { Automated innovation is an unsupervised machine } \\
\text { learning technique that can automatically extract } \\
\text { significant mathematical relationships from } \\
\text { Pareto-optimal solution sets. It can provide a } \\
\text { direction for industrial components recognition. }\end{array}$ \\
\hline $\begin{array}{l}\text { 2016/A Suitable Artificial } \\
\text { Intelligence Model for Inventory } \\
\text { Level Optimization [15] }\end{array}$ & $\begin{array}{l}\text { Tereza } \\
\text { Sustrova }\end{array}$ & $\begin{array}{l}\text { The paper illustrated their findings that } \\
\text { Artificial neural networks models could } \\
\text { be used for inventory management and } \\
\text { lot-sizing problem successfully }\end{array}$ & $\begin{array}{l}\text { The research also focuses on finding what } \\
\text { architecture of the artificial neural networks model } \\
\text { is the most suitable for subsequent prediction. }\end{array}$ \\
\hline $\begin{array}{l}\text { 2018/ Design and application of } \\
\text { the Internet of things-based } \\
\text { warehouse management system for } \\
\text { smart logistics [22] }\end{array}$ & $\begin{array}{l}\text { Lee, C.K.M; } \\
\text { Lv, Yaqiong; } \\
\text { Ng, K.K.H; } \\
\text { Ho, William; } \\
\text { Choy, K.L }\end{array}$ & $\begin{array}{l}\text { This paper discussed the importance of } \\
\text { the demand for real-time data, and } \\
\text { contextual information is required. }\end{array}$ & $\begin{array}{l}\text { This paper mainly focuses on the highly customised } \\
\text { orders, which is a small batch size but with great } \\
\text { variety and frequent changing. As for the higher } \\
\text { range at the receiving stage of a warehouse, its } \\
\text { methodology provides a useful reference. }\end{array}$ \\
\hline
\end{tabular}

The majority of the literature still concentrates on the supply chain management field, including order fulfilment and production plan [14], [23], [36], [39]-[41]. Yuan proposed a model based on web service[42]. It outlines the 
detailed steps to build an entire Automatic Identification system to perform material handling. Bandaru et al. generalized an Intelligent framework using genetic programming in warehouse management using unsupervised machine learning [10].

Moreover, the model design is focused on genetic scheduling ordering systems in the area of wholesale trade. Dou et al. introduced a hybrid solution using a genetic algorithm to solve scheduling problems in warehouse management. The paper focused on the production plan and order by using a Reinforcement Learning in Multi-robot system for Intelligent warehouse [20]. Tereza examined suitable artificial neural networks and their application in business operations, especially in the wholesale trade fields in 2016 [15]. The methods that the author adopted consist of artificial neural networks and ANN-based modelling. Mao et al. studied the resource scheduling optimisation problem in the system. They proposed a scheduling method of the intelligent warehouse management system based on the cloud model [31].

Since 2015, more and more research has focused on combining warehouse management with artificial intelligence applications. Although the classification and quantity management of the receiving stage is an essential function of warehouse management, very few studies have examined the warehouse receiving stage. Therefore, the receiving stage is still a gap which needs to be explored further by researchers in this field.

\section{Classical NeURAL Network Models AND ARCHITECTURES}

AI technologies have had broad applications in security and business fields, including warehouse management [37], [43]-[47]. However, there is no AI-based application for object identification and counting at the receiving stage of warehouse management. This section presents a review of recent literature on object classification, identification, and counting through the neural network system.

These available classical neural network models are not designed for warehouse management specifically. The principal theories, algorithms and structures can be extended to the domain of inventory management are detailed here to provide a reference for future researchers.

TABLE III: “ClassiCAL” NEURAL NETWORK MODELS ON OBJECT CLASSIFICATION, IDENTIFICATION AND COUNTING BETWEEN $2015-2019$

\begin{tabular}{lll}
\hline \hline Year/Title & Author(s) & Key Points \\
\hline $\begin{array}{l}\text { 2016/Faster R-CNN: } \\
\text { Toward Real-Time }\end{array}$ & $\begin{array}{l}\text { Ren, He, } \\
\text { Girshick, }\end{array}$ & $\begin{array}{l}\text { The state-of-the-art Faster R-CNN provided RPN } \\
\text { (Regional Proposal Network) algorithms to }\end{array}$ \\
$\begin{array}{l}\text { Region Proposal } \\
\text { Network [45] }\end{array}$ & and Sun & $\begin{array}{l}\text { perform object detection and classification. This } \\
\text { model output is in two sections; one is object } \\
\text { probability, and the other part is a regression. } \\
\text { Both the accuracy and run-time showed a } \\
\text { significant improvement. }\end{array}$
\end{tabular}

2016/SSD: Single Liu, This paper presents a method for detecting objects
Shot MultiBox Anguelov, in images using a single deep neural network Detector [57] Erhan, Experimental results on the PASCAL VOC, MS Szegedy, COCO, and ILSVRC datasets verified the SSD Reed, Fu, model has comparable accuracy, achieving $75.1 \%$ and Berg mAP.

2016/A Recent Trend Ghazvini, This paper explored and defined the effectiveness
in Individual Counting Abdullah, of CNN approaches applied to count individuals

Approach Using Deep and Ayob and achieved a high precision result.

\section{Research Area Limitations}

Faster R-CNN introduced predicted bounding boxes and gave reduced test time based on PASCAL VOC 2007 and MS COOC datasets. This model training time is longer. If we modified this model for use in warehouse management, a vast image database set is required. However, the current industry warehouse parts' images are generally small compared to VOC and ImageNet.

The SSD model mAP accuracy is higher than other object detection models. It cannot meet industry warehouse higher data accuracy requirements. However, it can provide a reference to build a better model, which is suitable for industry warehouse parts detecting and counting.

\section{Making use of CNN to identify and classify individuals} and count their number can be an appropriate reference for industrial parts. Nevertheless, as for industrial parts, their contours are diverse, so this needs further investigation.

\begin{tabular}{lll}
\hline 2017/Drone-based & Hsieh, & $\begin{array}{l}\text { This paper proposed Layout Proposal Networks } \\
\text { Object Counting by }\end{array}$ \\
$\begin{array}{l}\text { Spatially Regularised } \\
\text { Regional Proposal }\end{array}$ & Hsu & $\begin{array}{l}\text { count and localise the target objects (e.g., cars) in } \\
\text { videos recorded by the drone. }\end{array}$
\end{tabular}

This paper proposed a model to count cars on the floor. It is excellent as a reference for building an industrial warehouse model to perform identification and counting.

network [50]

\begin{tabular}{llllr}
\hline $\begin{array}{l}\text { 2018/Blur image } \\
\text { identification with }\end{array}$ & Wang, Li, & This paper integrated the existing popular \\
ensemble & and & Convolutional network model Simplified \\
convolutional neural & Zhang & $\begin{array}{l}\text { Fast_AlexNet } \\
\text { networks [37] }\end{array}$ & $\begin{array}{l}\text { Simplified_Fast_GoogLeNet (SFGN) to create } \\
\text { the proposed model to analyse blurred images. }\end{array}$
\end{tabular}

This paper proposed a better solution by combining these two existing models to explore the blurred image identification issues. Further, they created their online public image dataset. It provides a reference for industrial warehouse applications, and a combined model might optimise industry parts identification and counting.

\begin{tabular}{|c|c|c|}
\hline $\begin{array}{l}2018 / \text { Identification of } \\
\text { the source camera of } \\
\text { images based on the } \\
\text { convolutional neural } \\
\text { network [34] }\end{array}$ & $\begin{array}{l}\text { Huang, } \\
\text { He, Zhu, } \\
\text { Xuan, } \\
\text { Liu, and } \\
\text { Chang }\end{array}$ & $\begin{array}{l}\text { This paper researched a method to identify the } \\
\text { source camera producing images based on a } \\
\text { convolutional network considering the prediction } \\
\text { result. }\end{array}$ \\
\hline
\end{tabular}

This paper presents a model which requires a limited image sample size. However, the proposed method is very creative to learn about issues when using a camera to capture the components in the warehouse.

\section{A. Classical Neural Network Models}

A series of recent studies have presented classification and counting models related to individuals, cars and other objects [32], [34], [35], [37], [48]-[51] which provide useful neural network model references for industrial component identification and counting research. There are already several well-known deep-learning Convolutional Neural Network (CNN) applications, such as AlexNet [47], [52], 
GoogLeNet [43], [53] and Faster R-CNN [45], [54] that have been proposed and demonstrated to be sufficient for image classification. These networks are all designed to recognise the objects in the images and are good options for industrial component

Classification and counting in warehouse management. Please refer to Table III for details. The literature in the table studies different object classification, identification and counting models.

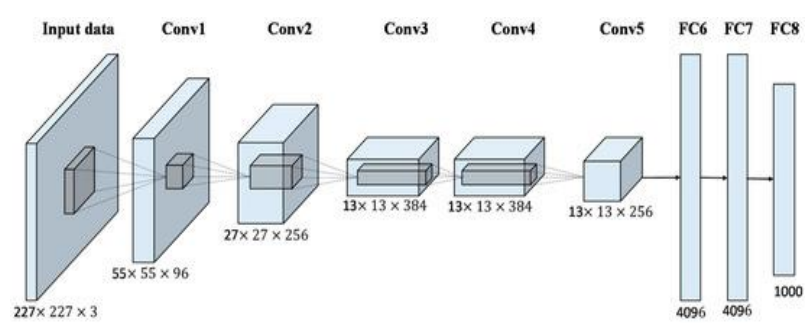

Fig. 1. AlexNet architecture [47].

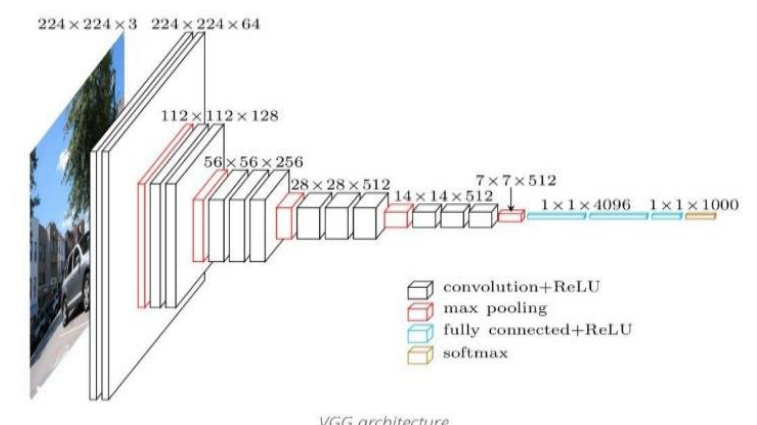

Fig. 2. VGG architecture [56].

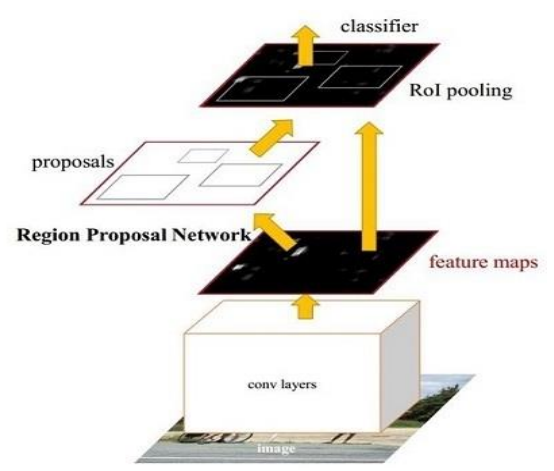

Fig. 3. Faster R-CNN architecture [45].

\section{B. Classical Neural Network Architectures}

This section introduces five conventional neural network model architectures, which can provide a reference for design-related warehouse models. AlexNet [52], VGG [55, 56], GoogLeNet [43], [53], Faster R-CNN [45], and SSD [57] are classical and prevailing successful CNN models. They can be used to meet several specific field applications and to design tasks for warehouse management after modification AlexNet was proposed in 2012. Fig. 1 shows the architecture of the AlexNet. VGG was introduced in 2014 and is a broadly adopted CNN model; its architecture is illustrated in Fig. 2. Based on VGG, Faster R-CNN provided an RPN (refer to Fig. 3 ) which increased the performance on both accuracy and efficiency. SSD (refer to Fig. 4). presents a CNN method to detect objects in images by using a single deep neural network, which provides a better reference for building a model at the receiving stage of the industrial warehouse management system [58]. GoogLeNet (refer to Fig. 5). was proposed in 2012, with four versions developed from Inception version 1 to Inception version 4 in 2016.

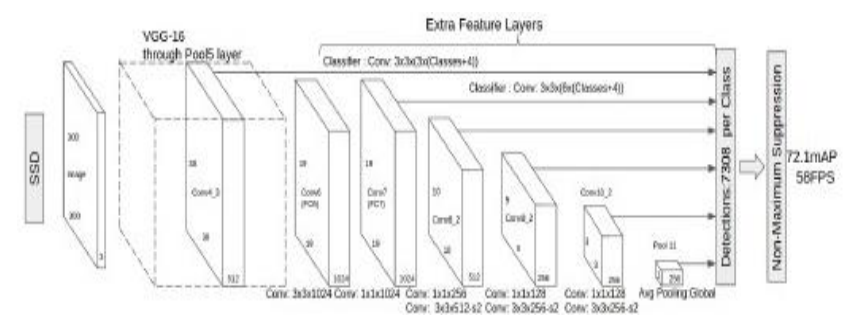

Fig. 4. SSD architecture [57]

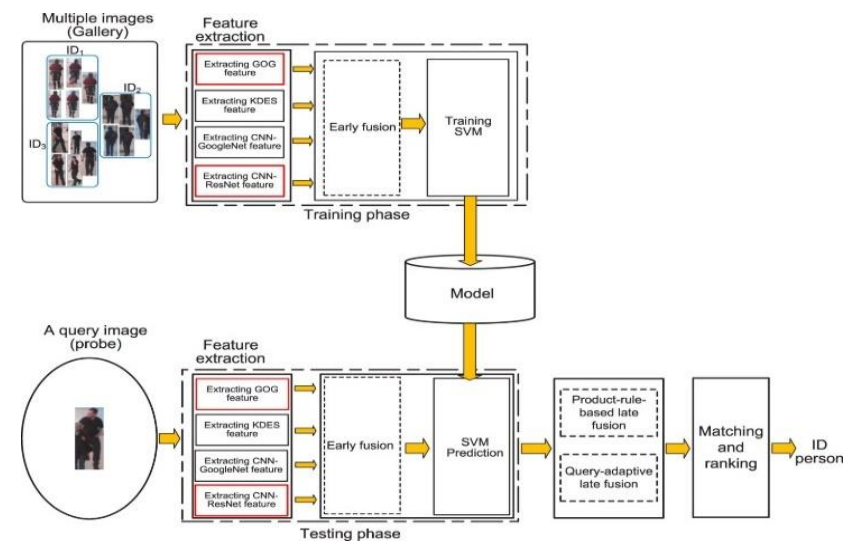

Fig. 5. GoogLetNet architectue [43].

These classical CNN architectures can be modified to achieve specific design goals by changing the number of hidden layers, weight parameters, and fine-tuning the output layers.

However, several issues need to be addressed for employing these structures in industry warehouse management system.

The first issue is the prediction accuracy of the CNN architectures. It is believed that CNN models have a higher prediction accuracy than any of the other simple neural networks [59, 60], Müller and Guido [61] and Geron [62] reported that the test results of MNIST datasets and Human Face datasets reach over $96 \%$ of accuracy. In contrast, the state-of-art Faster R-CNN [45] model can only achieve a $78.8 \% \mathrm{mAP}$ of accuracy. The accuracy of Faster R-CNN was obtained through extensive training data using MSCOCO [63], VOC2007 and VOC2012 datasets [64]. As for industrial warehouse data, there are no available datasets for selection and training and the training time is over 8 hours [46]. The SSD model's mAP is similar to Faster-R-CNN. Both the accuracy and training time cannot meet the requirements of warehouse management, which requires higher accuracy and must suit the real-time environment. In the industrial field, the enterprise management system requires the physical item quantity to be in conformance with the item quantity in the system; therefore, a $100 \%$ accuracy rate is the target.

The second issue is that the industrial database sets a shortage issue. These classical neural networks usually adopt current available standard database sets. The database sets include PASCAL VOC2007, ImageNet [65], MSCOCO and CIFAR-10 [66], and the database has a broad size range (from $200 \mathrm{Mb}$ to $4 \mathrm{~GB}$ ). Depending on the industry or business organisations, the size of the database is usually smaller 
compared with these available databases. In an industrial company, the category number of components usually are 3000-5000; therefore, these available database sets are not suitable for training a warehouse model.

Lastly, these classical models are typically implemented in Python code, TensorFlow or Caffe as the working platform. These platforms require higher hardware requirements, given that the massive computation load requires 16GM GPU memory, E5-1630 v3 @3.7GHz_4 processor [32], [46], [67] are necessary.

\section{COMPUTER VISION APPLICATION IN OBJECT CLASSIFICATION AND COUNTING}

Computer vision [68], [69] is an interdisciplinary scientific field which is used to deal with how computers can be enabled to gain a high-level of understanding from digital images or videos. From the perspective of engineering, it seeks to automate tasks that human visual systems can do [70]. This technology has been widely used to perform face recognition and object classification and tracking. OpenCV [68], [69] is the most comprehensive open-source to realise computer vision.

\section{A. OpenCV Approaches to Object Classification and Tracking}

OpenCV provides a series of application program interfaces (APIs) and algorithms to achieve the target of image processing and object identification and classification. These APIs include contour detection [71], [72] and colour space tracking [73] used in the classification, tracking and counting of objects. OpenCV and its open resources provide a series of techniques to execute these functions [68], [72]. Contour analysis, Harris corner detection [74]-[76], Canny edges [71], [77], [78], colour space tracking [73], [79], [80] and template matching [81], [82] are usually adopted to perform object tracking, identification and counting which can help to solve numerous issues requiring clarification in the industry field [34], [68], [74], [83]-[85].

\section{B. Classical Model Applications}

Khalid et al. [86] proposed a framework which can achieve a time-saving valid shape matching and retrieval framework from vast datasets. It provides an option to perform classification and counting by using shape matching in a warehouse model. Contour application is another approach to perform classification and counting in warehouse management. Gong et al. [72] reviewed a series of approaches to perform feature extraction to realise the classification target.

Computer vision can reach high accuracy to perform object classification and identification. However, some complicated issues cannot be solved, such as occluded objects in the image, blurred images, and untagged images [69]. Therefore, when designing a warehouse management model for the receiving stage, three steps should be considered, namely sliding windows selection, image feature extraction and classifier design.

It is, therefore, necessary to combine classical Neural Network models discussed in Section III and Computer
Vision methods to achieve the design task at the receiving stage in the warehouse.

\section{Challenges}

Several questions need to be addressed when starting to assemble the architecture of the designed network. These questions include image dataset definition and building, convolutional network layers confirmation, optimisation and loss function, training/test/verification data volume and test ratio and prediction accuracy [20], [21], [50], [85].

The classical neural networks for object detection, classification and counting have demonstrated promising improvements, and this provides a direction for future researchers to explore a better model at the receiving stage in warehouse management [22], [45], [57], [72], [83], [87].

Another consideration is to reduce training time and reach the real-time processing target. For some industrial fields, it is essential to build a model for target object classification and counting, which can meet the real-time requirement. SSD presented an approach to perform counting of objects in images and meet the real-time demand. However, the mAP is just $75.1 \%$, a rate of lower $80 \%$ is not acceptable to perform classification in warehouse management.

Computer Vision technology provides a series of APIs to track and count objects. These APIs include template matching, contour detection and Canny edges, which are better solutions to achieve object classification and counting for mini-size datasets.

Very few papers mentioned objects occluded by other objects in an image. It is difficult to detect or classify occluded objects. Depending on the level of the occlusion, the required task, especially in warehouse management, can be very challenging.

One research direction is to analyse the accurate number of objects which are occluded by the other objects in the image. The previous researches were based on visual attributes and trained CNN and computer vision [88], [89]. The occluded objects are not apparent visually in the image. In the practical scenario, such as in industrial warehouse management, many components are stacked together. On this basis, human experience, area, weight and objects density can be fully utilised in conjunction with $\mathrm{CNN}$ and computer vision to predict the accurate number of objects.

\section{CONCLUSIONS}

This paper reviewed the literature from 2000-2019 covering warehouse management, neural network-based object classification and counting and computer vision applications. A total of 82 among 154 pieces of literature examined, including books, were identified as relevant in this review. Overall, the research of the warehouse receiving stage is not substantial enough when compared to other elements of the supply chain management. Several important points are summarised as:

The research on image classification is the most dominant in this field, especially by using classical neural networks 
architecture and computer vision technology to meet both real-time classification and counting.

There are various combined approaches to achieve the target of image classification and counting. It is noticed that VGG and faster R-CNN are more prevalent due to the test speed and prediction accuracy. They are much better than other models for adopting this technology into warehouse management; however, the accuracy still needs to be improved to an acceptable level.

These existing papers mostly focused on recognise individuals, animals and other large-sized objects. The objects are convenient to recognise from the image,

considering the diversity of industrial components; the building of database sets is a critical element of the research.

The development of new approaches to combine the neural network model and computer vision seems necessary for the development of optimal future outcomes.

\section{CONFLICT OF INTREST}

The authors declare that there are no conflicts of interest regarding the publication of this paper.

\section{AUTHORS CONTRIBUTIONS}

Judy X Yang conducted the research, analysed the data, and wrote the first version paper. Dr Lily D. Li and Professor Mohammad Rasul guided analysis revised the article and approved the final version.

\section{REFERENCES}

[1] J. D. Edward. (2019). Supply Chain Execution. [Online]. Available: https://www.jdedwardserp.com/functional-modules/supply-chain-logi stics/

[2] SAP. Australia. (2019). Support Offerings. [Online]. Available: https://www.sap.com/australia/products.html

[3] G. Atwal, "Trends in warehouse management," Supply Chain Europe, vol. 20 , no. 3, pp. 36-37, 2011 .

[4] N. Faber, M. B. M. de Koster, and A. Smidts, "Organizing warehouse management," International Journal of Operations \& Production Management, vol. 33, no. 9, pp. 1230-1256, 2013.

[5] M. Joëlle, "Warehouse management," Logistics, pp. 47-70, Hoboken, NJ, USA: John Wiley \& Sons, 2018

[6] J. Scioscia, "Optimising warehouse management: Best practices for warehouse layout and training are crucial for implementing a management solution," Pharmaceutical Technology Europe, vol. 26, no. 2, p. 46, 2014.

[7] A. J. C. Trappey, C. V. Trappey, L. Ma, and A. C. C. Chang, Incorporating Data Warehouse Technology into Asset Information Management Systems for Large Assets, pp. 601-612, 2016.

[8] O. A. Grace and O. O. Timothy, "Information and communications technology and inventory management amongst breweries in Nigeria," Journal of Information Systems Engineering and Business Intelligence, vol. 4, no. 1, pp. 39-45, 2018.

[9] B. Emami-Mehrgani, W. P. Neumann, S. Nadeau, and M. Bazrafshan, "Considering human error in optimizing production and corrective and preventive maintenance policies for manufacturing systems," Applied Mathematical Modelling, vol. 40, no. 3, pp. 2056-2074, 2016.

[10] S. Bandaru, T. Aslam, A. Ng, and K. Deb, "Generalized higher-level automated innovation with application to inventory management," European Journal of Operational Research, vol. 243, no. 2, p. 480, 2015.

[11] G. Baryannis, S. Dani, and G. Antoniou, "Predicting supply chain risks using machine learning: The trade-off between performance and interpretability," Future Generation Computer Systems, vol. 101, pp. 993-1004, 2019.

[12] M. Qiu and Y. Song, "Predicting the direction of stock market index movement using an optimized artificial neural network model," PloS One, vol. 11, no. 5, pp. e0155133-e0155133, 2016.
[13] A. Gunasekaran and E. W. T. Ngai, "Expert systems and artificial intelligence in the 21st-century logistics and supply chain management," Expert Systems With Applications, vol. 41, no. 1, pp. $1-4,2014$.

[14] S. M. Bragg, Inventory Best Practices, 2nd ed. Hoboken Hoboken, N.J.: Hoboken: John Wiley \& Sons, Inc., 2011.

[15] S. Tereza, "A suitable artificial intelligence model for inventory level optimization," Trendy Ekonomiky a Managementu, vol. 10, no. 25, pp. 48-55, 2016

[16] M. Allen, "The development of an artificial intelligence system for inventory management using multiple experts," ProQuest Dissertations Publishing, 1986.

[17] D. Onoro-Rubio and R. J. Lopez-Sastre, "Towards perspective-free object counting with deep learning," ECCV, p. 16, 2016.

[18] W. T. Barcode, "The barcode warehouse enhances customer service for hepburn," Total Telecom Online, 2010.

[19] V. Manthou and M. Vlachopoulou, "Bar-code technology for inventory and marketing management systems: A model for its development and implementation," International Journal of Production Economics, vol. 71, no. 1, pp. 157-164, 2001.

[20] J. Dou, C. Chen, and P. Yang, "Genetic scheduling and reinforcement learning in multirobot systems for intelligent warehouses," Mathematical Problems in Engineering, Article pp. 1-10, 2015.

[21] B.-I. Kim, R. J. Graves, S. S. Heragu, and A. S. Onge, "Intelligent agentmodeling of an industrial warehousing problem," IIE Transactions, Article vol. 34, no. 7, p. 601, 2002.

[22] C. K. M. Lee, Y. Lv, K. K. H. Ng, W. Ho, and K. L. Choy, "Design and application of internet of things-based warehouse management system for smart logistics," International Journal of Production Research, vol. 56, no. 8, pp. 2753-2768, 2018.

[23] A. Diabat, K. Govindan, and V. V. Panicker, "Supply chain risk management and its mitigation in food industry," International Journal of Production Research, vol. 50, no. 11, pp. 3039-3050, 2012.

[24] M. Gibson, "Supply chain network optimization," MHD Supply Chain Solutions, vol. 41, no. 3, pp. 42-43, 2011.

[25] F. Hamdi, A. Ghorbel, F. Masmoudi, and L. Dupont, "Optimization of a supply portfolio in the context of supply chain risk management: literature review," Journal of Intelligent Manufacturing, vol. 29, no. 4 pp. 763-788, 2018.

[26] R. Hlioui, A. Gharbi, and A. Hajji, "Replenishment, production and quality control strategies in the three-stage supply chain," International Journal of Production Economics, vol. 166, p. 90, 2015.

[27] S. W. Ji, Y. Tian, Z. H. Zhang, and H. L. Lu, "Research on the FMCG supply chain quality control tower system and operation mechanism," Advanced Materials Research, vol. 694, pp. 3610-3613, 2013.

[28] J. P. v. D. Berg and W. H. M. Zijm, "Models for warehouse management: Classification and examples," International Journal of Production Economics, vol. 59, no. 1, pp. 519-528, 1999.

[29] J. Fulcher, "Bluetooth-enabled barcode scanners boost warehouse productivity," Manufacturing Business Technology, vol. 27, no. 6, p. 8, 2009.

[30] A. Johnson, "Training for warehouse staff.(Brief article)," Manufacturers' Monthly, vol. 00, no. 00, p. 62, 2008.

[31] J. Mao, H. Xing, and X. Zhang, "Design of Intelligent Warehouse Management System," An International Journal, vol. 102, no. 2, pp. 1355-1367, 2018.

[32] T. Les, M. Kruk, and S. Osowski, "Automatic recognition of industrial tools using artificial intelligence approach," Expert Systems with Applications, vol. 40, no. 12, pp. 4777-4784, 2013.

[33] E. Frazelle, World-Class Warehousing and Material Handling, New York: McGraw-Hill, 2001.

[34] N. Huang, J. He, N. Zhu, X. Xuan, G. Liu, and C. Chang, "Identification of the source camera of images based on convolutional neural network," Digital Investigation, vol. 26, pp. 72-80, 2018.

[35] C. Siegfarth, T. Voegtle, and C. Fabinski, "Comparison of two methods for $2 \mathrm{~d}$ pose estimation of industrial workpieces in images ${ }_{\text {в }}$ “ $\mathrm{CNN}$ vs. classical image processing system," The International Archives of the Photogrammetry, Remote Sensing and Spatial Information Sciences, vol. XLII-1, no. 1, pp. 401-405, 2018.

[36] E. Sweeney, D. B. Grant, and D. J. Mangan, "Strategic adoption of logistics and supply chain management," International Journal of Operations \& Production Management, vol. 38, no. 3, pp. 852-873, 2018.

[37] R. Wang, W. Li, and L. Zhang, "Blur image identification with ensemble convolution neural networks," Signal Processing, vol. 155, pp. 73-82, 2019

[38] B. Knill, "Systems integration and automatic identification," Material Handling Engineering, vol. 46, no. 7, p. 60, 1991. 
[39] R. M. R. C. U. M. Cantón Croda, D. E. D. G. U. M. G. Romero, and S O. S. C. U. M. C. Morales, "Sales prediction through neural networks for a small dataset," International Journal of Interactive Multimedia \& Artificial Intelligence, Article vol. 5, no. 4, pp. 35-41, 2019.

[40] Y. Wang, S. Wallace, B. Shen, and T.-M. Choi, "Service supply chain management: A review of operational models," European Journal of Operational Research, vol. 247, no. 3, p. 685, 2015.

[41] B. D. Williams and T. Tokar, "A review of inventory management research in major logistics journals," The International Journal of Logistics Management, vol. 19, no. 2, pp. 212-232, 2008.

[42] Y. Yuan, X. Hu, and J. Yang, Research and Implementation on Web Services Integration of Automatic Identification System, pp. 1-4, 2011

[43] P. Tang, H. Wang, and S. Kwong, "G-MS2F: GoogLeNet based multi-stage feature fusion of deep CNN for scene recognition," Neurocomputing, vol. 225, pp. 188-197, 2017.

[44] R. Girshick, Fast R-CNN, pp. 1440-1448, 2015.

[45] R. Shaoqing, H. Kaiming, R. Girshick, and S. Jian, "Faster R-CNN: Towards real-time object detection with region proposal networks," IEEE Transactions on Pattern Analysis and Machine Intelligence, vol. 39, no. 6, pp. 1137-1149, 2017

[46] H. L. Li, Y. Huang and Z. Zhang, "An improved faster R-CNN for same object retrieval," IEEE Access, vol. 5, pp. 13665-13676, 2017.

[47] L. Ding, H. Li, C. Hu, W. Zhang, and S. Wang, "Alexnet feature extraction and multi-kernel learning for object-oriented classification," International Archives of the Photogrammetry, Remote Sensing and Spatial Information Sciences - ISPRS Archives, vol. XLII-3, no. 3, pp. 277-281, 2018

[48] T. Islam, M. A. Rico-Ramirez, D. Han, and P. K. Srivastava, "Artificial intelligence techniques for clutter identification with polarimetric radar signatures," Atmospheric Research, vol. 109-110, pp. 95-113, 2012.

[49] N. G. Bardeh and M. Palhang, New Approach for Human Detection in Images Using Histograms of Oriented Gradients, pp. 1-4, 2013.

[50] H. Meng-Ru, L. Yen-Liang, and W. H. Hsu, Drone-Based Object Counting by Spatially Regularized Regional Proposal Network, pp. 4165-4173, 2017.

[51] Z. Wu, X. Chen, Y. Gao, and Y. Li, "Rapid target detection in high-resolution remote sensing images using yolo model," The International Archives of the Photogrammetry, Remote Sensing and Spatial Information Sciences, vol. XLII-3, no. 3, pp. 1915-1920, 2018.

[52] L. Ding, H. Li, C. Hu, W. Zhang, and S. Wang, "Alexnet feature extraction and multi-kernel learning for objectoriented classification," The International Archives of the Photogrammetry, Remote Sensing and Spatial Information Sciences, vol. XLII-3, pp. 277-281, 2018.

[53] Studies from Nanjing University provide new data on science (artifact removal using improved GoogLeNet for sparse-view CT reconstruction), Science Letter, p. 1650, 2018.

[54] R. Gandhi, R-CNN, Fast R-CNN, Faster R-CNN, YOLO - Object Detection Algorithms, 2018.

[55] M. Mateen, J. Wen, S. Nasrullah, Z. Song, and Z. Huang, "Fundus image classification using VGG-19 architecture with PCA and SVD," Symmetry, vol. 11, no. 1, 2019.

[56] A. Selimovic, B. Meden, P. Peer, and A. Hladnik, Analysis of Content-Aware Image Compression with VGG16, pp. 1-7, 2018.

[57] L. Wei, D. Anguelov, C. Szegedy, S. Reed, C.-Y. Fu, and A. Berg, "SSD: Single shot multibox detector," ArXiv.org 9905, pp. 21-37, 2016.

[58] A. Ghazvini, S. N. H. S. Abdullah, and M. Ayob, "A recent trend in individual counting approach using deep network.(report)," International Journal of Interactive Multimedia and Artificial Intelligence, vol. 5, no. 5, p. 7, 2019.

[59] N. Andrew, AI Is the New Electricity, O'Reilly Media, Inc., 2013.

[60] A. NG. (2017). Deep learning. Youtube. [Online]. Available: https://www.youtube.com/watch?v=ArPaAX_PhIs\&list=PLkDaE6sC Zn6Gl29AoE31iwdVwSG-KnDzF

[61] A. C. M. S. Guido, Introduction to Machine Learning with Python, O'Reilly Media, Inc., 2013

[62] Hands-On Machine Learning with Scikit-Learn and TensorFlow: Concepts, Tools, and Techniques to Build Intelligent Systems, O'Reilly, 2017.

[63] Cocodataset. [Online]. Available: http://cocodataset.org/\#home

[64] P. Voc. [Online]. Available: http://host.robots.ox.ac.uk/pascal/VOC/

[65] ImageNet. [Online]. Available: http://www.image-net.org/

[66] CIFAR. [Online]. https://www.cs.toronto.edu/ kriz/cifar.html

[67] Y. N. Jeng and C. H. Wu, "Frequency identification of vibration signals using video camera image data," Sensors, vol. 12, no. 10, pp. 13871-13898, 2012.
[68] K. Pulli, A. Baksheev, K. Kornyakov, and V. Eruhimov, "Real-time computer vision with OpenCV," Communications of the ACM, vol. 55, no. 6, pp. 61-69, 2012.

[69] J. Howse, OpenCV Computer Vision with Python, Olton: Olton: Packt Publishing, Limited, 2013.

[70] Computer vision definition. [Online]. Available: https://en.wikipedia.org/wiki/Computer_vision

[71] A. J. Coia and M. A. Crognale, "Contour adaptation reduce the spreading of edge induced colours," Vision Research, vol. 151, pp. 135-140, 2018.

[72] X.-Y. Gong, H. Su, D. Xu, Z.-T. Zhang, F. Shen, and H.-B. Yang, "An overview of contour detection approaches," International Journal of Automation and Computing, vol. 15, no. 6, p. 656, 2018.

[73] P. Hidayatullah and M. Zuhdi, "Color-texture based object tracking using HSV color space and local binary pattern," International Journal on Electrical Engineering and Informatics, vol. 7, no. 2, pp. 161-174, 2015.

[74] E. Rosten, R. Porter, and T. Drummond, "Faster and better: A machine learning approach to corner detection," IEEE Transactions on Pattern Analysis and Machine Intelligence, vol. 32, no. 1, pp. 105-119, 2010.

[75] H. Yang, Y. Ma, H. Yang, and M. Li, "Parts shape recognition based on improved Harris corner detection algorithm," Journal of Computers, vol. 9 , no. 10, p. 2371, 2014.

[76] L. Yi-Bo and L. Jun-Jun, "Harris corner detection algorithm based on improved contourlet transform," Procedia Engineering, vol. 15, no. C, pp. 2239-2243, 2011.

[77] A. P. Thombare and S. B. Bagal, A Distributed Canny Edge Detector: Comparative Approach, pp. 312-316, 2015.

[78] Z. Yang and P. I. Rockett, "The Bayesian operating point of the canny edge detector," IEEE Transactions on Image Processing, vol. 15, no. 11, pp. 3409-3416, 2006.

[79] F. Laguzet, M. Gouiffes, L. Lacassagne, and D. Etiemble, Automatic Colour Space Switching for Robust Tracking, pp. 295-300, 2011.

[80] X. Lu and K. Nishiyama, "Low-resolution colour-based visual tracking with state-space model identification," Computer Vision and Image Understanding, vol. 114, no. 9, pp. 1045-1054, 2010

[81] D. Ceylan, M. Dang, N. J. Mitra, B. Neubert, and M. Pauly, "Discovering structured variations via template matching," Computer Graphics Forum, vol. 36, no. 1, pp. 76-88, 2017.

[82] S. Korman, D. Reichman, G. Tsur, and S. Avidan, "Fast-match: Fast affine template matching," International Journal of Computer Vision, vol. 121, no. 1, pp. 111-125, 2017.

[83] C. Stauffer and W. E. L. Grimson, "Adaptive background mixture models for real-time tracking," in Proc. the IEEE Computer Society Conference on Computer Vision and Pattern Recognition, 1999, vol. 2, pp. 246-252.

[84] Patent issued for computer vision-based object tracking system (USPTO 9964624), Journal of Engineering, p. 3327, 2018.

[85] M. Sergiu and D. A. Sergiu, "A computer vision approach to object tracking and counting," Studia Universitatis Babes-Bolyai: Series Informatica, vol. 55, no. 3, pp. 121-130, 2010.

[86] S. Khalid, B. Sabir, S. Jabbar, and N. Chilamkurti, "Precise shape matching of large shape datasets using a hybrid approach," Journal of Parallel and Distributed Computing, vol. 110, pp. 16-30, 2017.

[87] B.-I. Kim, R. J. Graves, S. S. Heragu, and A. S. Onge, "Intelligent agent modelling of an industrial warehousing problem," IIE Transactions, vol. 34, no. 7, pp. 601-612, 2002.

[88] Abdullah and M. S. Hasan, An Application of pre-Trained CNN for Image Classification, pp. 1-6, 2017.

[89] H. Omori, K. Hanyu, M. Yamashita, and S. Shimada, Prediction of the Visual Similarity Between Photos using Several Pre-Traind CNNs, pp. 168-173, 2018.

Copyright $\odot 2021$ by the authors. This is an open-access article distributed under the Creative Commons Attribution License which permits unrestricted use, distribution, and reproduction in any medium provided the original work is properly cited (CC BY 4.0).

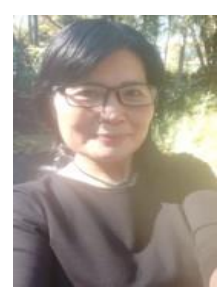

Judy X. Yang received her bachelor of agricultural machinery degree from Henan Agricultural University, China. She studies the master of informatics by research at CQUniversity, Australia since June 2019 Her research focuses on machine learning application in supply chain management. She has worked in manufacturing engineering and supply chain management fields over 18 years. Her work history includes in an America manufacturing company Penn 
Engineering in Shanghai as a project mechanical engineer and MIS electrical company as an OEM project engineer. She is a member of the Engineers Australia since 2015.

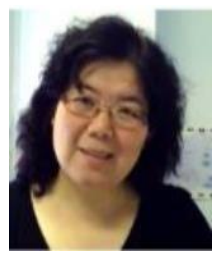

Lily Li received a B Eng. from Xi'an Jiaotong University, China, an MIT from the University of Newcastle, Australia, a PhD and a Grad. Cert. in Tertiary Education from CQUniversity, Australia. Dr $\mathrm{Li}$ has been a full-time academic at CQUniversity since 2002. Her experiences consist of course coordination, teaching and learning management, curriculum design and research. Dr Li's research interests include computational intelligence, evolutionary optimisation and software engineering. She is a member of the Australia Computer Society.

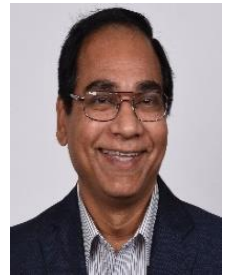

Mohammad Rasul has obtained his $\mathrm{PhD}$ from The University of Queensland, Australia. Currently, he is a professor of mechanical engineering at the School of Engineering and Technology, Central Queensland University, Australia. $\mathrm{He}$ is specialised and experienced in research and teaching in clean energy and thermodynamics. He has made significant contributions in research with over 450 publications, 4700 citations in Scopus and $\$ 3.4$ million research grants. He has supervised $30 \mathrm{PhD} /$ Master of Engineering Research students to completion. He is involved with professional communities through his varied roles such as membership of engineers Australia, various conference committees, editorship and grant assessors. 